\title{
Teorías lingüísticas y disciplinas prácticas. Promisoria relación para las salas de clase
}

\author{
Magdalena Viramonte-Ávalos* \\ Universidad Nacional de Córdoba, Argentina
}

En el curso de los últimos años, que por inmediatez existencial es siempre percibido como precipitado y complejo, quienes estamos en la arena de las Ciencias del Lenguaje hemos asistido, en nuestro país de residencia, a un sugerente proceso de mutación de intereses que se han develado en variados espacios científicos pero, particularmente, en la elección de temas focales para trabajos de indagación. Tomada esas indagaciones en su conjunto, puede observarse cómo el tratamiento de hechos de praxis, en particular, de habilidades lingüísticas en sujetos pertenecientes a grupos clausos (aulas primarias, secundarias o universitarias) creció cuantitativamente sobre los que atienden a la mera especulación en torno a teorías lingüísticas o propuestas hermenéuticas del lenguaje humano.

Así, por ejemplo, en solicitudes de subsidios o de becas, en programas de congresos o de foros, se presentan numerosos documentos descriptivos y/o propositivos sobre modos deficitarios o no de escritura, de lectura o de interacción verbal, con variados diseños metodológicos, con metas de corto o de largo plazo, atendiendo a distintos niveles de edad y a diversidad de realidades y de geografías.

\footnotetext{
* Para correspondencia dirigirse a: Magdalena Viramonte-Ávalos (mavalos@ucor.ar), Centro de Investigaciones Lingüísticas, Facultad de Lenguas, Universidad Nacional de Córdoba, Av. Vélez Sarsfield 187, 5000, Córdoba, Argentina.
} 
En esos documentos puede apreciarse siempre la referencia a uno o a varios marcos teórico-conceptuales, configurantes de la tarea, pero con prevalencia de los que se inscriben en el amplio campo interdisciplinario de la Lingüística Aplicada.

Por otras parte, la experiencia de compartir preocupaciones en los ámbitos de las salas de clase nos ha permitido entender la necesidad del docente y del investigador de dar cabida a la búsqueda de soluciones frente a cuestiones consideradas "urgencias" en las instituciones educativas: desde las más drásticas como hambre, enfermedad, violencia, pasando por las menos drásticas pero también disolventes, como apocamiento afectivo-cognitivo (desidias, negaciones, silencios, singulares sombras del ámbito familiar), hasta otras insertas en las tecno-problemáticas, cualquiera de ellas o en su conjunto, relacionada de manera directa o indirecta con habilidades lingüísticas del alumnado, sin importar edades.

Se entiende entonces que emerja el intento de encontrar respuestas ad hoc porque hay que resolver encrucijadas que involucran a grupos humanos en circunstancias precisas de tiempo y espacio y que deben "cumplir un programa". Entonces se van perfilando en el aula propuestas específicas de trabajo. No nos referimos a las muchas de ese tipo que brotan improvisadamente a veces con éxito, a veces no. Nos referimos a las que se originan, por un lado, en los análisis críticos del docente a la hora de evaluar material de clase, de donde extrae casuísticas que se repiten, constituyendo regularidades (por ejemplo, de ciertos errores) y, por otro, en teorías lingüísticas que iluminan las factibilidades de aplicación. Este es el germen de una "disciplina práctica".

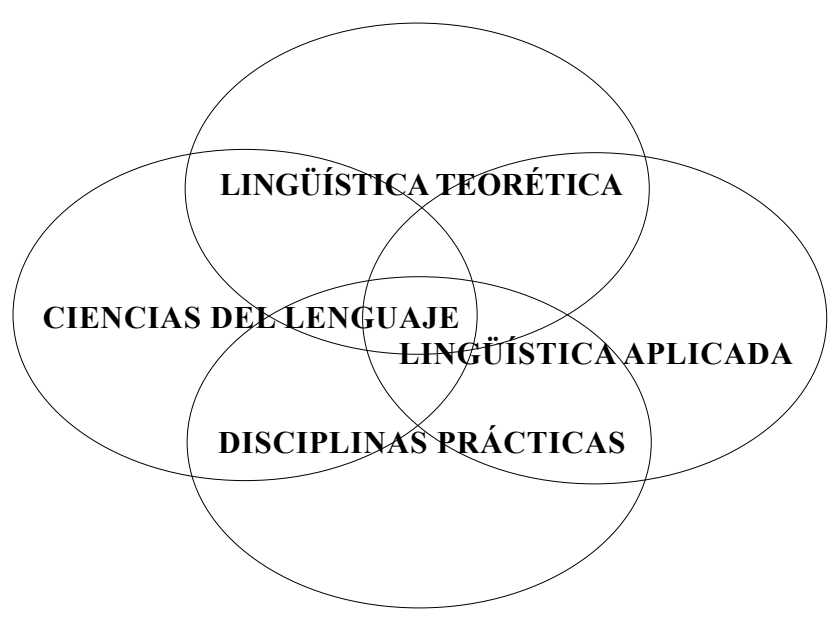


Lo que vemos abstractamente diagramado, nos parece de particular importancia para la historia de la educación lingüística en nuestros países sudamericanos. Devela avidez de respuesta a realidades severamente complejas, porque en ellas están comprometidos centralmente los problemas de aprendizaje, relacionados con variables antes impensadas en los análisis. Hoy, esos análisis obligan a una sutil atención a todo dato que el medio ofrezca.

Algunas de las "urgencias" aludidas más arriba serán motivo de una breve reflexión para relacionarlas con los aprendizajes lingüísticos.

\section{APRENDIZAJES LINGÜÍsticos, SALUD Y LOGROS ESCOLARES}

Un espacio que requiere cada vez mayor vigilia es el de la relación entre salud-nutrición y desempeños lingüístico-cognitivos. Un estudio en marcha, diseñado interdisciplinariamente, nos recuerda que el crecimiento y desarrollo normal del sujeto implican un buen estado de salud psico-físico y emocional, pero en la base se encuentran nutrición y conducta sanitaria adecuadas para promover la normalidad en los procesos cognitivos, en particular, atención y memoria. El aprendizaje adecuado del lenguaje se inserta en estas pre-condiciones.

Habida cuenta de la tragedia del hambre que marca estigmas en muchas comunidades, es fácil comprender cuán urgida está la escuela de hoy por encontrar paliativos.

\section{DiSYUNCIÓN ESCUELA-FAMILIA}

La escuela del siglo XXI ya no es de puertas adentro. La comunidad circundante cobra cada vez mayor protagonismo y, para bien o para mal, esa escuela ya no toma sola las grandes decisiones.

A modo de ejemplo, las investigaciones referidas a la intervención familiar antes y durante la escolarización en lo que hace a adquisición y desarrollo de la lecto-escritura van mostrando cuánto se puede lograr sumando esfuerzos. Narración temprana para la adquisición de esquemas, juegos compartidos con los docentes para el enriquecimiento del léxico, intervención paternomaternal en relatos familiares y un largo, largo etcétera jalonan los caminos señalados con signos positivos.

Por el contrario, el costo cognitivo en el rendimiento escolar del niño habituado a criarse sin diálogo doméstico, se ha manifestado como una 
penosa desventaja. Consecuencia de ello, el ímprobo esfuerzo docente para la reparación, no siempre coronada con éxito.

\section{ILETRISMO FUNCIONAL}

Sugerentes páginas de sociología de la lectura y de la escritura se refieren al iletrismo o analfabetismo funcional. Se trata de un interesante estado de cosas: se sabe leer y escribir, pero ello no alcanza para sobrevivir en el mundo digitalizado actual.

En Nativos digitales, Alejandro Piscitelli (2009) lanza una enérgica advertencia: "La disyunción es clara; o los inmigrantes digitales aprenden a enseñar distinto o los nativos digitales deberán retrotraer sus capacidades cognitivas..."

El problema que esto supone para la labor docente en no importa qué nivel, debe ser considerado como otra de las urgencias educativas actuales.

Ya lo sabemos: presupuestos exiguos, debilidad en la formación de recursos humanos, desigualdad de oportunidades, y mucho más aparecerá en el listado de las argumentaciones, sean a favor o en contra de las conversiones programáticas. Pero si no se comienza, las salas de clase se nos vaciarán porque -en palabras del mismo autor citado- "la educación debe convertirse en industria del deseo si quiere ser industria del conocimiento".

A la luz de las tres problemáticas expuestas, cada una de ellas perteneciente a niveles de realidad diferentes y que de manera alguna pretenden contemplar la totalidad, volvemos la mirada a las disciplinas prácticas y comprendemos -en ese entramado de urgencias del panorama social- por qué se están haciendo presentes en las aulas: porque intentan proveer posibles soluciones a angustiantes búsquedas de maestros, profesores, alumnos, directivos, padres, ONG, centros, etc., en plazos breves, con especificidad y eficacia.

Decíamos que esas disciplinas van constituyéndose en el seno de la propia labor del aula, por ejemplo, cuando se descubren regularidades en errores y se intenta analizarlos, para luego formular una explicación. El apoyo de teorías lingüísticas es clave tanto en esa etapa como en la de propuesta de ejercitaciones para la superación del error.

Ahora bien, ¿a qué teorías recurrir?

El siglo XX nos dejó como fecundo producto teorías que no merecen olvido sino reanálisis, por cuanto en la riqueza intrínseca de su cosmovisión del lenguaje humano pueden contribuir con holgura y adecuación al presente. 
En un intento riesgoso por el costo que tiene siempre una elección -lo no elegido no es necesariamente un disvalor- haremos referencia a la semántica léxica de Eugenio Coseriu y cómo de ella puede derivar una propuesta de praxis, en una zona tan neurálgica como la de adquisición y desarrollo léxicos.

Hablar implica señalar las cosas del mundo para que el otro las recoja y se establezca el diálogo. Para señalar las cosas del mundo está la mediatización de las palabras. Las palabras no viven fuera de nosotros. Viven en nosotros. En nuestras memorias, en nuestros lexicones. Nuestros lexicones se construyen dinámicamente, pero las etapas escolares son vitales: la escuela tiene la oportunidad de proveer un útil, bello y abundante entramado léxico en las memorias semánticas de cada uno de los educandos para que sobre ellos no caiga el peso de la queja "qué pobreza". Para que, al contrario, puedan ejecutar los verbos de Neruda: atraparlas, limpiarlas, agitarlas, emperejilarlas, libertarlas...

¿Cómo podría colaborar una parte de la teoría de semántica léxica de E Coseriu para que en las aulas se vaya constituyendo una disciplina lexicológica práctica, en el curso de las enseñanzas y aprendizajes de la lectura y de la escritura en no importa qué asignatura?

\section{SEMÁNTICA, SIGNIFICADO Y LÉXICO}

Coseriu se propone estudiar la organización propiamente lingüística del léxico, considerándolo un sistema (a pesar de que es el dominio menos estructurado de la lengua) y toma como modelo la fonología. Las unidades que estudia son los lexemas, portadores de significado.

Decía Coseriu (1987):

Lingüisticamente hablando lo primario no es la designación sino el significado porque la estructura idiomática significa primariamente algo y solo por su significado puede emplearse para la designación de lo extralingüístico.

El significado es la base semántica de la investigación de las lenguas porque es el contenido dado en y por una lengua.

Al seleccionar el contenido, excluye la designación (referencia a lo extralingüístico o lo extralingüístico mismo) y el sentido (plano semántico del texto).

Ahora bien, distingue cinco tipos de significado (léxico, categorial, instrumental, estructural y óntico) e indica dónde puede comprobarse el significado léxico, mediante una serie de distinciones previas: 


\section{Distinciones previas para un estudio estructural del léxico y para llegar a los objetos de investigación homogéneos} Cosas
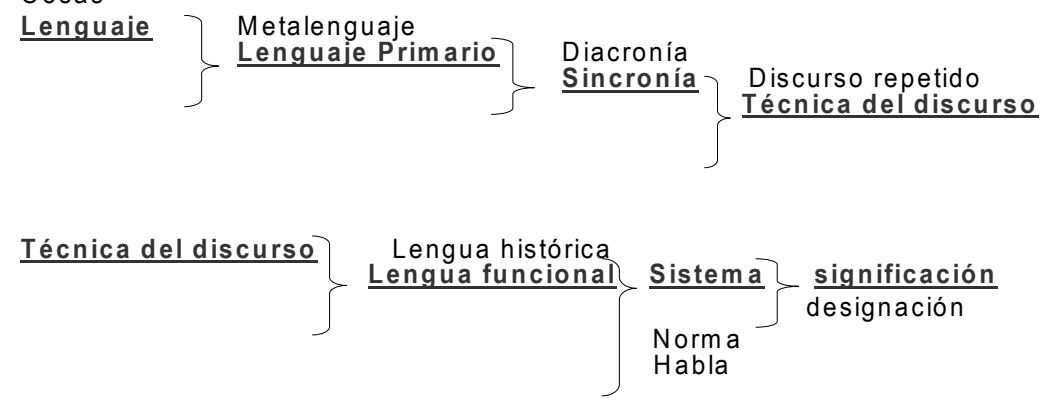

Este rico entramado de las distinciones previas para poder llegar a los significados léxicos abre caminos para trabajar la disponibilidad léxica, la riqueza léxica, la relación del léxico con la evocación, la comparación entre el nombre y el objeto, las terminologías escolares -tan poco atendidas en la actualidad-, las fraseologías y paremiologías culturalmente marcadas. Cobijados en una teoría del lenguaje que permite la apertura a la dinámica discursivo-pragmática, quienes guían el proceso de desarrollo de competencias cognitivo-lingüísticas pueden intentar el diseño programático del aula. Vaya a modo de ejemplo:

1) Para advertir las diferencias entre conocimiento de las cosas y conocimiento del lenguaje, es pertinente el ejercicio de "evocaciones". Con ellas se trabaja disponibilidad léxica, a partir de la cual, se puede discriminar la pertenencia de las palabras a mundos diferentes, vgr.

Canario: palabras que evoca (disponibilidad)....... jaula/mascota

Caballo: palabras que evoca (disponibilidad)....... campo/carro

En este ámbito de praxis, se construye la reflexión sobre el cúmulo de palabras del lexicón y la manera cómo ellas se "en-redan" siempre con escenarios del mundo ${ }^{1}$. Pero, además, la de las palabras en sí: "canario" y "mascota" son distintas porque cada una de ellas organiza una realidad y es portadora de un significado.

1 Esta ejercitación es muy productiva en grupos de niños o de adolescentes cuyas vidas transcurren en barrios conflictivos, ya que permite al docente configurar mundos y detectar realidades. 
2) El tema de las diferencias ente lenguaje y metalenguaje abre las vías al trabajo con la terminología, área poco atendida hasta ahora, en la escuela primaria. Por ejemplo, en la propia gramática, hacer tomar conciencia de que llamamos sustantivo a una palabra "X" pero que "sustantivo" pertenece a la gramática, como "teorema" a la matemática o "falla" a la geografía.

Para docentes y alumnados es una riquísima tarea porque puede ampliar los límites de las conceptualizaciones y permite diseños metodológico específicos.

3) En cuanto a las diferencias entre técnica del discurso y discurso repetido, posibilita - entre muchas opciones- trabajar lo relacionado con hechos de la historia de la lengua, por ejemplo, permanencia de dichos o refranes que se siguen "citando sin cambio alguno" y cuyas ejercitaciones de sustitución entretejen variados caminos gramaticales:

$>$ siempre se dice "gato por liebre" (y no "por conejo") puede sustituirse por un verbo: engañar

\section{PARA CONCLUIR}

Hemos querido contribuir para que voces del siglo XX regresen al corazón de las aulas, se acerquen, iluminen propuestas, abran vías de existencia a diversas disciplinas prácticas, tan necesarias hoy por lo útiles, ágiles, oportunas, adecuadas, y se comprenda que ellas aportan ricos entramados interdisciplinarios.

José Antonio Marina en Movilización Educativa dice:

La preocupación universal por la educación ha generado un sistema de excusas en el que todo el mundo echa las culpas al vecino. Los padres a la escuela, la escuela a los padres, todos a la televisión, la televisión a los espectadores, al final acabamos pidiendo soluciones al gobierno, que apela a la responsabilidad de los ciudadanos, y otra vez a empezar. En esta rueda infernal de las excusas podemos estar girando hasta el día del juicio. La única solución que se me ocurre es no esperar a que otros resuelvan el problema, sino preguntarme: ¿qué puedo hacer yo para solucionarlo? 
Ojalá esta nota que se propuso esbozar el tema de las disciplinas prácticas y que es germen de un extenso trabajo en preparación, sirva para que colegas docentes que ya están haciendo esta labor puedan presentarla a la comunidad educativa. De esa manera, la suma de propuestas, contribuirá a un rico cruce de teorías y de praxis para una pluralidad de situaciones. 


\section{REFERENCIAS BIBLIOGRÁFICAS}

Arens, Hans. 1969. La lingüística, sus textos y su evolución desde la antigüedad hasta nuestros días. Gredos: Madrid.

Blakemore, Sarah-Jayne y Uta Frith. 2008. Cómo aprende el cerebro. La claves para la educación, con prólogo de José A. Marina. Barcelona: Ariel.

Coseriu, Eugenio. 1977. Principios de semántica estructural. Madrid: Gredos.

- 1978. Gramática, semántica, universales. Madrid: Gredos.

1987. Curso de gramática contrastiva (inédito). Universidad Nacional de Córdoba.

Di Tullio, Ángela y Magdalena Viramonte de Ávalos. 2003. Educación lingüística integral. Ejercitación léxico gramatical diaria para despertar la conciencia léxica. Córdoba: Comunicarte.

Feld, V. y J. Eslava-Coвo (comps.). 2009. La perspectiva histórico-cultural de Vigotsky y la neurofisiología. Buenos Aires: Noveduc.

GeCKeler, Horst. 1984. Semántica estructural y teoría del campo léxico. Madrid: Gredos.

Piscitelli, Alejandro. 2009. Nativos digitales. Buenos Aires: Santillana. 